\title{
Evidence synthesis from a qualitative and a quantitative systematic literature review combined with a focus group interview to identify relevant criteria for decision-making on management options for early pregnancy loss
}

\author{
Mirjam Peters ${ }^{1,2}$, Andrea Icks ${ }^{2}$ and Charalabos-Markos Dintsios ${ }^{2 *}$ \\ ${ }^{1}$ Department of Applied Health Sciences, Midwifery, Hochschule für Gesundheit, Bochum, Germany \\ ${ }^{2}$ Centre for Health and Society, Institute for Health Services Research and Health Economics, Medical Faculty, Heinrich-Heine University Düsseldorf, Düsseldorf, \\ Germany
}

\begin{abstract}
Purpose: Three management options for the treatment of Early Pregnancy Loss (EPL) exist: (i) surgery, (ii) expectant management, and (iii) medical management. Our aim was to identify relevant criteria for women to make a management decision.

Patients and methods: Our triangulation approach comprise a systematic review of the qualitative and quantitative literature on management preferences of women with EPL and a focus group to verify the literature findings.

Results: Nine potentially relevant decision criteria could be identified: avoidance of inpatient treatment with anaesthesia and surgery, avoidance of injuries at uterus and cervix, avoidance of blood transfusions, avoidance of drug side effects, avoidance of bleeding and pain, Experience EPL as natural process, avoidance of seeing the foetus, Avoidance of uncertainty when the abortion takes place, and have a short period of EPL completion. It was shown that the qualitative literature reported more criteria than those used in published quantitative preference elicitation studies. These were especially psychological criteria and criteria concerning the respective setting.

Conclusion: Evidence synthesis from qualitative and quantitative literature and a focus group interview could identify relevant criteria for decision-making on management options in case of EPL. It is important to include the women's perspective into the criteria selection.
\end{abstract}

\section{Introduction}

An Early Pregnancy Loss (EPL) is the natural death of an embryo or foetus and occurs in ten to twenty percent of all pregnancies. This article focuses on incomplete EPL and missed miscarriage in the first trimester of pregnancy, in contrast to a complete miscarriage or an EPL occurring later in pregnancy $[1,2]$.

According to the American Congress of Obstetricians and Gynaecologists, we will use the term Early Pregnancy Loss (EPL) instead of miscarriage or Early Pregnancy Failure (EPF) to avoid the association with miss or failure [3]. This could coincidently lead to a negative association. Also, the term patients will not be used for women with EPL, because no medicalization of healthy women is intended.

Considering EPL, there are three possible management options: (i) One option is surgery, mostly dilation and curettage or vacuum aspiration in general or local anesthetic. A stay in hospital or in an outpatient operations center is necessary. Other options are (ii) expectant management, which means waiting for the EPL to complete itself, or (iii) medical management were this process is sped up using misoprostol. Possible side effects are bleeding and pain, and it's possible to see the fetus. The existing evidence is limited but does not indicate a superiority of one of the three management options. They are different according to length of time until EPL is complete and in terms of invasiveness [3-7].
Women after EPL have an increased risk for symptoms of anxiety, depression, and grief. Moreover, a substantial minority will develop long-term psychological impairment, like depression, anxiety, obsessive-compulsive disorder or posttraumatic stress disorder [8,9]. A recent review suggests that women have strong and diverse preferences for EPL management. They reported higher satisfaction when treated according to their preferences [10].

Management preferences can differ between medical professionals and patients $[11,12]$. Hence, the elicitation of patients' preferences can be used to choose relevant outcomes in planning studies, and it can be implemented at all levels in the health care system. At the macrolevel, patients' preferences can impact reimbursement decisions. At the mesolevel, they can be incorporated in medical guidelines and the

*Correspondence to: Charalabos-Markos Dintsios, Centre for Health and Society, Institute for Health Services Research and Health Economics, Medical Faculty, Heinrich-Heine University Düsseldorf, Düsseldorf, Germany, Tel: +49 211 8116664, Fax +49 2118119778 , E-mail: dintsios@hhu.de

Key words: early pregnancy loss, method triangulation, qualitative systematic review, quantitative systematic review, focus group, evidence synthesis

Received: October 15, 2019; Accepted: October 31, 2019; Published: November 04,2019 
Peters M (2019) Evidence synthesis from a qualitative and a quantitative systematic literature review combined with a focus group interview to identify relevant criteria for decision-making on management options for early pregnancy loss

development of evidence-based patient information. Additionally, at the micro-level, they can structure shared decision-making [13-15].

The Guidelines International Network (G-I-N) lists only one guideline of EPL management. According to the National Institute for Health and Care Excellence (NICE) there should be used expectant management for 7-14 days as first line management for women with vaginal bleeding or with no fetal heartbeat. All three management options should be discussed with the women to allow them to make an informed choice [4]. The Practice Bulletin on Early Pregnancy Loss from the ACOG recommends offering all three options to the women [3]. Studies about the medical treatment in the USA and in the Netherlands indicate that women are not offered all three options by the medical professionals. Studies suggest that medical management and surgical management are mostly performed in case of EPL [10,16,17].

This study aims to identify relevant criteria for women to make a management decision for EPL and to gather context information about women with EPL to prepare a quantitative preference elicitation.

\section{Material and methods}

Our triangulation approach consisting of a systematic review of the quantitative and qualitative literature on management preferences of women with EPL, and, furthermore, a focus group aimed at taking account of women views as far as possible. The latter was conducted to verify the literature findings and to identify possible criteria which have not been described yet.

\section{Review}

\section{Search strategy and selection}

We performed a systematic literature search in October 2015 on treatment preferences of women who had experienced an EPL. Sensitive topic-based search strategies were designed for each of the following major databases: Current Contents, CINAHL, EMBASE, Journals@OVID, MEDLINE/ PubMed, PsycINFO, The Cochrane Libary and Web of Science. We supplemented this search by searching reference lists of the identified articles. Our search strategy combined terms of EPL with terms capturing decision analysis or preferences. We included qualitative and quantitative studies in English or German. The inclusion was not restricted with respect to publication date or country. The literature search was periodically updated during 2016 to identify new publications up to manuscript finalization.

The search strategy for Web of Science (Thomas Reuters) serves as an example. The search was conducted at October $10^{\text {th }} 2015$ and resulted in 27 matches: ((miscarriage OR early pregnancy loss OR (spontaneous abortion AND (early pregnancy OR first trimester)) OR early pregnancy failure OR first trimester pregnancy failure OR first trimester pregnancy loss)) AND: ((stated preference ${ }^{\star}$ OR patient preference ${ }^{\star} \mathrm{OR}$ willingness to pay OR willing to pay OR wtp OR analytic hierarchy process ${ }^{\star}$ OR ahp OR conjoint OR discrete choice OR multi - criteria ${ }^{\star}$ OR multicriteria ${ }^{\star}$ OR multi - attribute* OR multiattribute ${ }^{\star}$ OR multi - objective oR multiobjective $^{\star}$ OR multi - alternative OR multialternative $e^{\star}$ OR multiple criteria OR multiple attribute ${ }^{\star}$ OR multiple objective $e^{\star}$ OR multiple alternative OR decision - analy ${ }^{\star} \mathrm{OR}$ decision - making OR patient ${ }^{\star}$ preference $^{\star}$ OR patient ${ }^{\star}$ prioriti ${ }^{\star}$ OR elicit $^{\star}$ patient ${ }^{\star}$ OR patient perception ${ }^{\star}$ OR patient values OR patient choice $^{\star}$ OR informed choice $\left.{ }^{\star}\right)$; ((miscarriage OR early pregnancy loss OR (spontaneous abortion AND (early pregnancy OR first trimester)) OR early pregnancy failure OR first trimester pregnancy failure OR first trimester pregnancy loss)) AND TITLE: (((perception* OR values OR choice $^{\star}$ AND (patient* OR woman OR women))).

An evaluation of the studies was conducted by two members of the research team independently (MP and CMD). A third person (AI) dealt with any discrepancies that occurred in the assessment of the full texts.

\section{Quality assessment}

The criteria of the Conjoint Analysis Application in Health - A Checklist were used to assess the quality of the quantitative studies if appropriated [18]. We utilized the methodology of the Qualitative Research Review Guidelines RATS and the Critical Appraisal Skills Program - quality assessment tool for qualitative studies to extract and characterize the methodological quality of each qualitative study $[19,20]$.

\section{Data extraction and synthesis}

Quantitative studies were described, and preference criteria were extracted. Qualitative Studies were described and were analyzed by line-by-line analysis to identify preference data. Subsequently, we conducted a thematic synthesis of the findings from the quantitative and the qualitative studies. The findings from the qualitative studies were assigned to the categories from the quantitative studies. Preference data from the qualitative studies which were not congruent to the criteria from the quantitative studies were grouped by similarity. Further, we defined a criteria name for each of these groups.

\section{Focus group}

\section{Study design, subjects and recruitment}

A focus group interview was performed to verify the extracted criteria from the systematic literature review, if necessary, to complete them and to find out if the results are transferable to the German population. Additionally, we aimed to analyze the language used in the target Group Interview.

Women with an EPL and consecutive EPL management in the past 10 years were recruited. The inclusion criteria were: (i) sufficient German language skills and (ii) sufficient cognitive skills for participating in a focus group. Furthermore, (iii) the participants had to be over 18 years old. They were recruited through three obstetric practices in the outpatient sector and through the cologne midwife network. Also, we recruited women through selected online forums and through administrators of five Facebook@ groups.

Subsequently, interested women received an information sheet and the inclusion criteria via E-Mail. After that, women could give their written consent.

\section{Conducting the focus group interview}

The focus group interview followed a semi-structured interview guide based on the criteria extracted from the literature. The experience with EPL management and the reasons for certain management decisions made by the women were the main topics of the focus group. Criteria were only brought in as indirect open questions if they were not addressed by the women themselves.

The group moderator (MP) opened the focus group interview with a short introduction and explained the three possible EPL management options. Then, the participants were asked to write down their management decision and their reasons and afterward they were invited to read it out loud. During the interview, they were invited to 
Peters M (2019) Evidence synthesis from a qualitative and a quantitative systematic literature review combined with a focus group interview to identify relevant criteria for decision-making on management options for early pregnancy loss

explain what was important for their decision. An extern assistant took field notes. The focus group was recorded and transcribed verbatim. The focus group took place in a seminar room at Cologne University. The moderator was familiar with the management of Group discussions. The participants were informed that the moderator was a midwife.

Qualitative content analyses of the transcripts and the field notes were performed with MAXQDA12@. Participant's statements about relevant criteria for a management decision by EPL were extracted. The statements were assigned to the criteria from the literature. If necessary, new categories were inductively named.

\section{Evidence synthesis: Integrating evidence from systematic reviews and the focus group}

Criteria from the literature that were evaluated as not important in the focus group were excluded. Also, criteria have been excluded if they were evaluated as relevant for the decision-making process but independent of the management options. Additionally, the wording of the criteria was adjusted to the language used by the interviewed women.

\section{Results}

\section{Characteristics and quality of the identified studies}

The systematic literature search yielded 192 hits (Figure 1). Additionally, two studies were found in the study reference lists and 24 were identified in a parallel systematic literature search for RCTs on EPL treatment. After removing duplicates, 216 hits remained for reviewing. We identified 97 abstracts for further analysis and screened 17 full-text articles. Moreover, studies were excluded because: (a) two studies reported treatment choices of participants without presenting reasons for choice [21], (b) three studies aimed on treatment preferences in pregnancy after EPL [22-24], (c) one study examined physician attitudes [25], (d) one study reported general experience of EPL [26], and (e) one was a letter referring to an included study without any additional information [27]. Three quantitative and six qualitative studies remained in the review. All studies obtained an ethical approval (Figure 1) [28,29].

\section{Quantitative studies}

Three quantitative studies on preferences for EPL management were found. Two of them were Stated Preference Discrete Choice Experiments, which examined the preferences of women for two or three of the three available management options [30,31]. Both studies were considered to be of sufficient methodological quality in accordance with the Conjoint Analysis Application in Health - A Checklist [18]. Ryan et al. [30] selected criteria because of their significant differences between the treatment options in an RCT. Petrou et al. [31] and Ryan et al. [30] chose similar criteria. Their criteria were based on a systematic literature search, the experience of the authors and extern advice from clinicians. The criteria were: (i) Time spent at the hospital receiving treatment, (ii) Level of pain experienced, (iii) Number of days of bleeding after treatment (only Petrou et al. [31]), (iv) Time taken to return to normal activities after treatment (Ryan and Hughes [30]: normal household activities), (v) Cost of treatment to women, and (vi) Chance of complications requiring more time or readmission to hospital (Ryan et al. [30]) Complications following treatment). Also, the levels of the criteria were very similar.

Petrou et al. [31] included women with missed abortion, incomplete miscarriage or early fetal demise in the first trimester of pregnancy,

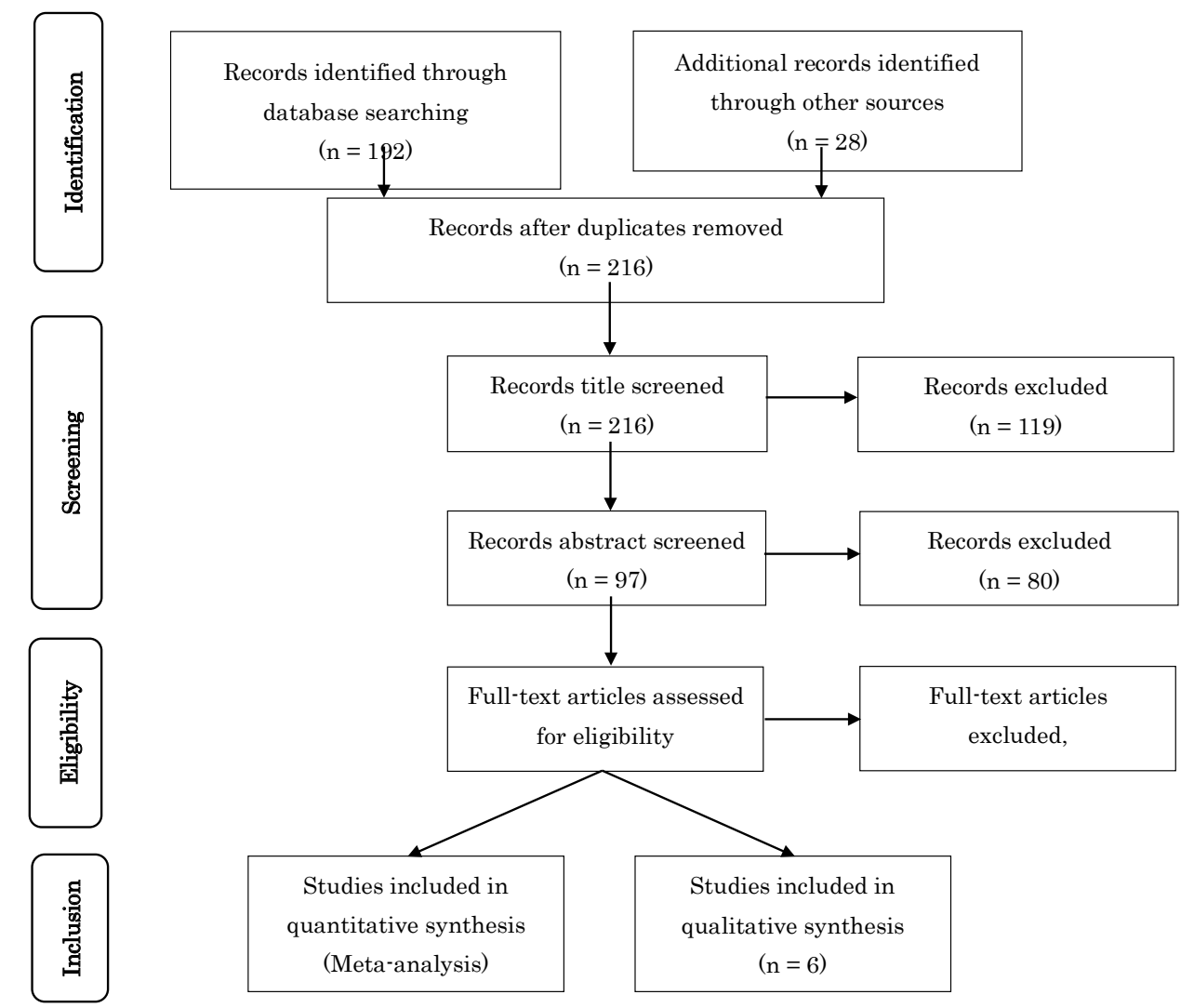

Figure 1. Flow chart for search and selection of studies based on PRISMA Statement [28,29] 
Peters M (2019) Evidence synthesis from a qualitative and a quantitative systematic literature review combined with a focus group interview to identify relevant criteria for decision-making on management options for early pregnancy loss

which participated in an RCT. Ryan et al. [30] included women independently from experiencing an EPL. 360 women in Petrou et al. [31] (response rate: 53\%) and 196 women in Ryan et al. [30] (response rate: $33 \%$ ) completed the respective questionnaires.

The preference results, based on the economic approach of willingness to pay to reflect the specific criteria relevance for the participants, vary between both studies. In both studies, the rating of the participant's willingness to pay differed strongly, although the categories were highly related to each other. Hence, the criterion lowering the chance of complications received the highest willingness to pay in the study by Ryan et al. [30]. However, this criterion was placed the second last place in the study of Petrou et al. [31]. The criterion pain played a very important role in both studies. It was identified as the most important criterion in the study of Petrou and McIntosh [31] and was ranked as second important in the study of Ryan et al. [30]. Besides, Time taken to return to normal activities after treatment reached a high willingness to pay in the study of Petrou et al. [31]. However, in the study by Ryan et al. [30] this criterion did not play a primary role at all for the investigated women. Regarding the criterion Time spent at the hospital receiving treatment, the study of Ryan et al. [30] showed a high willingness to pay among the women. In contrary, the study of Petrou et al. [31] showed a low priority regarding this criterion.

Graziosi et al. [32] used a Standard Gamble Approach to assess the preferences of women with EPL for treatment with misoprostol compared with a surgical management. The study group consisted of 64 women with EPL participating in an RCT. Fifty percent of the women would choose misoprostol if its success rate is $65 \%$. Hence, they were asked for the reasons for their decisions. The answers were categorized in bleeding, avoiding a surgery and a natural process.

\section{Qualitative studies}

Four of the six qualitative studies deemed to be of high quality, and two were of sufficient quality assessed with RATS [19]. The studies with sufficient quality were Molnar et al. [33] and Wijesinghe et al. [34]; they did not provide information on data analysis. Two studies were conducted in the USA, two in the UK, one in Denmark and one in Sri Lanka. Five studies recruited in hospitals, and one in an outpatient setting [35]. Molnar et al. [33] used a general hospital sample with women between 18 and 45 years, five studies included women with recent EPL experience. Participants in four of these studies had the chance to choose at least between two of the three abovementioned treatment options. In one study, the participants were interviewed after they took part in an RCT arm on expectant treatment [34]. Some qualitative studies followed a RCT allowing the participants to choose their treatment options, some not. The studies represent 218 participants in total, with a range from 6 to 75 participants. All in all, data was collected through face-to-face interviews or telephone interviews. In three studies data collection was standardized and validated by triangulation [35-37]. Table 1 summarizes the study and participants' characteristics.

\section{Statements in qualitative studies and fit with criteria from quantitative studies}

The quotes that described relevant criteria for the decision about treatment for EPL were extracted. Some findings of the qualitative studies fit into the extracted criteria from the quantitative studies (Table 2).

In most of the studies, the women mentioned pain and bleeding. The women experienced different levels of pain. Some experienced it as tolerable, others as severe: "don't remember actually, it was more like period pain [...] ... then I was fine." [36]. "I was in terrible terrible pain... when I couldn't take the pain anymore; it was as if my arms and my legs were becoming very cold and everything was changing" [38]. Also, the women's bleeding was reported as very variable.

The criterion Time taken to return to normal activities after treatment is represented through the quote: “... but we had tickets to go out, and we had the babysitter organized, and we were having a weekend away on our own" [36].

The women did not express experiences which could be related to the following criteria from the quantitative studies: Time spent at the hospital receiving treatment, Cost of treatment to women and Chance of complications requiring more time or readmission to hospital.

\section{Statements from the qualitative studies were assigned to the criteria from the quantitative studies}

Many findings did not fit the criteria from the quantitative studies. These findings were grouped by similarity and were named: Setting of the abort, natural method, invasiveness of the treatment method, recommendations of others, the medical procedure is similar to an abortion, there is too little information about this management option, Avoidance of seeing the foetus, Uncertainty when and where the abortion takes place (Table 3 ).

In the following, quotations are presented: One important issue was time, one woman said: "because you're going through your grief all of the time that you are waiting for it to go, and then it goes, and you do a sort of mental realignment or whatever, you know, you have time to sort of prepare yourself." [36], but another woman said: "It would've been better if some kind of method was used to remove this without wasting time." [34]. Also, some women set their self a timeframe after which they would rethink their management decision: "I had thought about doing the DઐC if it, if um, the, if I didn't actually miscarry on my own in a week [35].

Another issue was the use of a natural method: "to choose to have a surgical procedure, wasn't me, isn't me. If there was a natural alternative, then there was far less intervention in that way. I would always go for that option." [38]. One woman felt to be assisted to miscarry naturally, she stated: “(...) the medical treatment, it's just speeding it up (...)" [36].

Women mentioned whether they want to be at home or not. One woman found it reassuring to be at home: "I'll be at home, I'll be safe, and if there're any real problems, I've got a phone number to ring" (31), one reason not be at home is described: “(.) having other children at home and not wanting to miscarry in front of them,(...)" [35].

\section{New formed criteria names for statements from qualitative studies which were not congruent to the criteria from the quantitative studies}

There was an occurring dichotomy in many cases. Some women assessed criteria as positive, while others considered the same as negative, like anesthesia or seeing the fetus. Hence, some reported fear of seeing the fetus, but an other woman reported:" ... and I picked it up, and I was going: Mum, Mum, come and have a look [laughs]." [36].

Two new qualitative studies were yielded in an update of the literature search at 16 December, $2016[39,40]$. Both studies confirm the criteria from the included studies and did not bring in any new criteria. 
Peters M (2019) Evidence synthesis from a qualitative and a quantitative systematic literature review combined with a focus group interview to identify relevant criteria for decision-making on management options for early pregnancy loss

Table 1. Study and participant characteristics of qualitative studies.

\begin{tabular}{|c|c|c|c|c|c|c|c|c|c|}
\hline \multirow[b]{2}{*}{ Study } & \multicolumn{5}{|c|}{ Study characteristics } & \multicolumn{4}{|c|}{ Participant characteristics } \\
\hline & Country & Aim & $\begin{array}{l}\text { Sample size and } \\
\text { Setting }\end{array}$ & Data collection & Data analysis & EPL experience & $\begin{array}{l}\text { Age } \\
\text { range }\end{array}$ & $\begin{array}{l}\text { Sociodemographic } \\
\text { status }\end{array}$ & Financing \\
\hline Limbo [35] & USA & $\begin{array}{l}\text { To extend } \\
\text { understanding of } \\
\text { women's experience } \\
\text { of miscarriage by } \\
\text { exploring their } \\
\text { approach to decide }\end{array}$ & 23, Medical Center & $\begin{array}{l}\text { Telephone interview, } \\
30-45 \text { min, process- } \\
\text { oriented interview } \\
\text { guide, follow up after } \\
\text { one year }\end{array}$ & $\begin{array}{l}\text { Dimensional analysis: } \\
\text { "line - by - line"; } \\
\text { discussed in a team } \\
\text { of five }\end{array}$ & $\begin{array}{l}2-4 \text { weeks after } \\
\text { EPL; } 15 \mathrm{~s}, 1 \mathrm{~m}, 7 \mathrm{e}\end{array}$ & $23-40$ & $\begin{array}{l}\text { High socioeconomic } \\
\text { status }\end{array}$ & $\begin{array}{l}\text { No } \\
\text { information }\end{array}$ \\
\hline Molnar [33] & USA & $\begin{array}{l}\text { Assess patient } \\
\text { preferences for } \\
\text { expectant treatment } \\
\text { compared with } \\
\text { dilatation and } \\
\text { curettage, and the } \\
\text { effect of physician } \\
\text { recommendation on } \\
\text { these preferences }\end{array}$ & $\begin{array}{l}\text { 75, university- } \\
\text { affiliated family } \\
\text { medicine clinic }\end{array}$ & $\begin{array}{l}\text { Telephone interview } \\
\text { with an evidence- } \\
\text { based scenario and } \\
\text { questions (1) likelihood } \\
\text { of choosing each } \\
\text { option }(\mathrm{e}, \mathrm{s})(2) \text { reasons } \\
\text { for their choice }(3) \\
\text { effect of physician on } \\
\text { recommendation }\end{array}$ & Quantitative analysis & $\begin{array}{l}27 \text { EPL, } 84 \text { no } \\
\text { EPL }\end{array}$ & $18-45$ & $\begin{array}{l}\text { Mostly European } \\
\text { descent; most highly } \\
\text { educated }\end{array}$ & $\begin{array}{l}\text { American } \\
\text { Academy } \\
\text { of Family } \\
\text { Physicians } \\
\text { and the } \\
\text { Washington } \\
\text { A. of F. }\end{array}$ \\
\hline Olesen [37] & Denmark & $\begin{array}{l}\text { To gain insight into } \\
\text { this process and } \\
\text { the circumstances } \\
\text { that may affect the } \\
\text { decision-making }\end{array}$ & $\begin{array}{l}6 \text { ( }+5 \text { health care } \\
\text { professionals), } \\
\text { emergency } \\
\text { department of a } \\
\text { university hospital }\end{array}$ & $\begin{array}{l}\text { Grounded Theory, semi- } \\
\text { structured interviews, } \\
\text { until saturation }\end{array}$ & $\begin{array}{l}\text { Inductive explorative } \\
\text { method: constant } \\
\text { comparative method; } \\
\text { discussed in a team } \\
\text { of three }\end{array}$ & $\begin{array}{l}\text { Treatment by } \\
\text { preference; s, } \\
\text { m \& e }\end{array}$ & $30-41$ & No information & $\begin{array}{l}\text { The Health } \\
\text { Foundation }\end{array}$ \\
\hline Ogden [38] & UK & $\begin{array}{l}\text { To explore women's } \\
\text { reasons for selecting } \\
\text { either expectant or } \\
\text { surgical management } \\
\text { and to examine the } \\
\text { impact of treatment } \\
\text { upon them }\end{array}$ & $\begin{array}{l}\text { 16, Early Pregnancy } \\
\text { and Gynaecology } \\
\text { Assessment Uni, } \\
\text { Hospital }\end{array}$ & $\begin{array}{l}\text { Qualitative in-depth } \\
\text { interviews: } 30-60 \mathrm{~min} .\end{array}$ & $\begin{array}{l}\text { Interpretative } \\
\text { Phenomenological } \\
\text { Analysis; Coming } \\
\text { through both authors }\end{array}$ & $\begin{array}{l}\text { About } 5 \text { weeks } \\
\text { after EPL, e \& s }\end{array}$ & $22-43$ & $\begin{array}{l}10=\text { white } \\
3=\text { black }\end{array}$ & $\begin{array}{l}\text { No extern } \\
\text { financing }\end{array}$ \\
\hline Smith [36] & UK & $\begin{array}{l}\text { To assess the } \\
\text { social and personal } \\
\text { impact of different } \\
\text { management } \\
\text { methods on women's } \\
\text { experience of the first- } \\
\text { trimester miscarriage }\end{array}$ & $\begin{array}{l}\text { 72, } 3 \text { hospitals, RCT } \\
\text { affiliated }\end{array}$ & $\begin{array}{l}\text { Interviews using a topic } \\
\text { guide and focus groups }\end{array}$ & $\begin{array}{l}\text { Iterative analysis } \\
\text { for common themes } \\
\text { (NUDIST), discussion } \\
\text { in the team and focus } \\
\text { groups, all participants } \\
\text { was invited to offer } \\
\text { any written comments } \\
\text { to the main findings }\end{array}$ & $\begin{array}{l}6 \text { months }-1 \\
\text { year after EPL } \\
\text { treatment, } 20 \mathrm{~s}, 18 \\
\mathrm{~m}, 18 \mathrm{e}, 16 \text { didn't } \\
\text { participate in the } \\
\text { RCT }\end{array}$ & $20-50$ & $\begin{array}{l}71 \text { white, mixed } \\
\text { socioeconomic } \\
\text { status, most middle } \\
\text { class }\end{array}$ & $\begin{array}{l}\text { Executive } \\
\text { Project } \\
\text { Grant }\end{array}$ \\
\hline $\begin{array}{l}\text { Wijesinghe } \\
{[34]}\end{array}$ & Sri Lanka & $\begin{array}{l}\text { To understand } \\
\text { the women's } \\
\text { perception of } \\
\text { symptoms, } \\
\text { acceptability, fertility } \\
\text { wishes and care } \\
\text { received of expectant } \\
\text { care }\end{array}$ & $\begin{array}{l}\text { 25, hospital, RCT } \\
\text { affiliated }\end{array}$ & $\begin{array}{l}\text { Interviews based on } 5 \\
\text { themes; } 60-90 \mathrm{~min}\end{array}$ & No information & $\begin{array}{l}\text { Expectant } \\
\text { treatment, two } \\
\text { weeks after } \\
\text { diagnosis }\end{array}$ & $20-45$ & High education & $\begin{array}{l}\text { National } \\
\text { Science } \\
\text { Foundation } \\
\text { of Sri } \\
\text { Lanka }\end{array}$ \\
\hline
\end{tabular}

S: Surgical; M: Medical; E: Expectant management.

Table 2. Statements from the qualitative studies were assigned to the criteria from the quantitative studies.

\begin{tabular}{|c|c|c|}
\hline Criteria from quantitative studies & Statements from qualitative studies & Coverage in qualitative studies \\
\hline Time spent at the hospital receiving treatment & No Information & No coverage \\
\hline Level of pain experienced & Degree of pain & $\begin{array}{l}\text { Odgen [38], Olesen [37], Smith [36], } \\
\text { Wijesinghe et al. [34] }\end{array}$ \\
\hline Number of days of bleeding after treatment & Degree of bleeding & $\begin{array}{l}\text { Odgen [38], Olesen [37], Smith [36], } \\
\text { Wijesinghe et al. [34] }\end{array}$ \\
\hline $\begin{array}{l}\text { Time taken to return to normal activities after } \\
\text { treatment }\end{array}$ & $\begin{array}{l}\text { Grieving for their lost baby - chance to say goodbye; Get it over with; To complete as quickly as } \\
\text { possible; Need for an ending; Could get on with their normal lives }\end{array}$ & $\begin{array}{l}\text { Odgen [38], Olesen [37], Smith [36], } \\
\text { Wijesinghe et al. [34] }\end{array}$ \\
\hline Cost of treatment to women & No Information & No coverage \\
\hline $\begin{array}{l}\text { Chance of complications requiring more time } \\
\text { or readmission to hospital }\end{array}$ & No Information & No coverage \\
\hline
\end{tabular}

\section{Results of the focus group}

One focus group interview with five participants was conducted in May 2016. All women who were invited to the focus group participated. Two of them were pregnant and one sleeping baby was present. The duration of the focus group was $90 \mathrm{~min}$. Participant's characteristics are summarized in Table four. Furthermore, all participants graduated at a university or a university of applied science. Two of the participants were between 18-29 years old, one between 30-39 years old, and two were between $40-49$ years old.

The results of the focus group interview are described as statements of the participants. The reported data is based on the focus groups Interview transcript and the written protocol. Women's quotations are translated from German into English. The statements were assigned to the literature-based criteria. There were no statements which made it necessary to define new criteria. 
Peters M (2019) Evidence synthesis from a qualitative and a quantitative systematic literature review combined with a focus group interview to identify relevant criteria for decision-making on management options for early pregnancy loss

There were some prior issues for the women referring to EPL, which were context information and helped to understand women with EPL. One big issue was the lack of information about the management options and other health service supplies like midwife service or psychosocial services and the medical staff's lack of sensibility towards the women. The existing information was often derived from informal sources from the internet. For the women, it was important to be accommodated in a reasonable setting in the hospital. Moreover, a sensitive language played an important role for the women. Also, they were unsecured about the diagnosis. For instance, some women feared to have a living baby being killed in course of the intervention (Table 4).

\section{Evidence synthesis (systematic reviews and focus group)}

The criteria avoid a blood transfusion and avoid side effects of drugs, like digestive disorders were added, although they weren't included in the preference literature nor they were mentioned in the focus group. In clinical RCTs they were identified as differences between the management options. It worked as a pendant to the mentioned complication Avoid cervical damage. Some criteria from the preference literature were excluded. The criterion cost of treatment to women was excluded because of the structure of the German statutory health insurance-based health system. Additionally, it was neither mentioned in the qualitative preference literature nor in the focus group. The criterion medical treatment is similar to an abortion was described in the literature as relevant but was discussed as irrelevant in the focus group. Therefore, it was excluded by the research team. Some studies reported recommendations of physicians or influence of family members or fellow patients as relevant [33-35,38]. The criterion Recommendation of another person was excluded, because it was not specific for one or two management options. Also, the criterion Little knowledge is available about this treatment was excluded, because it refers to the social context and not the management option itself. Two studies reported that there was too little information given from healthcare professionals to women about the options, which led to a feeling of being unprepared, especially for the women with expectant management $[36,38]$. The criterion Time taken to return to normal activities after treatment was excluded, because the characteristics for all three management options were similar.

The wording of the criteria was adjusted to the language of the target population. For example, for the criterion Avoidance of seeing the foetus/ the child, the foetus/the child instead of the fetus was used, because some women preferred the child and others the foetus in their narratives (Table 5).

\section{Discussion}

The aim of this study was to identify relevant criteria for the decision-making processes for EPL Management. These criteria could also be used for the preparation of quantitative preference elicitation studies. Nine potentially criteria could be identified: (i) Avoidance of a treatment in hospital with anaesthesia and surgery, (ii) Avoidance of injuries at uterus and cervix, (iii) Avoidance of a blood transfusion, (iv) Avoidance of side effects of drugs, like digestive disorders, (v) Avoidance of strains through bleeding and pain, (vi) Experience EPL as natural process/ „let the body handle it“, (vii) Avoidance of seeing the fetus, (viii) Avoidance of uncertainty when the abortion takes place, (ix) Have a short period of time until EPL is completed.

The systematic literature search identified three quantitative preference studies. These studies reported some criteria, and these criteria were exclusively physical criteria. The criteria were construed based on literature and experts. The authors of both discrete choice experiments conclude that the women's preferences were a function of the criteria given in the study and no criteria were omitted. Although the criteria were similar, the results between both studies differed among each other.

The evidence from the six qualitative studies indicates that there exist more relevant criteria for the women with EPL than those reported in the quantitative studies. Especially, psychological criteria or criteria concerning the type of care and the treatment setting were not included in the quantitative studies. The criteria identified in our study also fit the three reasons bleeding, avoiding a surgery and a natural process gathered by [32].

Table 3. New formed criteria names for statements from qualitative studies which were not congruent to the criteria from the quantitative studies.

\begin{tabular}{|c|c|c|}
\hline $\begin{array}{l}\text { Criteria developed from statements of } \\
\text { qualitative studies }\end{array}$ & Statements from qualitative studies & Source \\
\hline Setting of the abort & $\begin{array}{l}\text { Not to be at home, } \\
\text { To be at home }\end{array}$ & $\begin{array}{l}\text { Limbo [35], Odgen [38], Olesen [37], Smith [36], } \\
\text { Wijesinghe et al. [34] }\end{array}$ \\
\hline Natural method & Naturally, "let the body handle it" & All studies \\
\hline Invasiveness of the method & $\begin{array}{l}\text { Fear of intervention, Less invasive } \\
\text { Fear of aesthetic, Anaesthesia being a relief }\end{array}$ & Molnar [33], Odgen [38], Olesen [37], Smith [36] \\
\hline The medical procedure is similar to an abortion & $\begin{array}{l}\text { Avoiding a procedure that could be construed as abortion; Make sure that the } \\
\text { pregnancy was not viable }\end{array}$ & Limbo [35], Smith [36] \\
\hline Seeing the foetus & Fear of seeing the foetus; Want to see the foetus & Olesen [37], Smith [36] \\
\hline $\begin{array}{l}\text { Uncertainty when and where the abortion takes } \\
\text { place. }\end{array}$ & Felt unprepared for how their miscarriage will be & Olesen [37] \\
\hline
\end{tabular}

Table 4. Anamnestic participant characteristics

\begin{tabular}{|c|c|c|c|c|c|}
\hline Number of Participant & 1 & 2 & 3 & 4 & 5 \\
\hline Number of births (without EPL, with stillbirth) & 1 & 0 & 2 & 0 & 2 \\
\hline Number of EPL & 1 & 1 & 3 & 2 & 1 \\
\hline Received information about the following management options (multiple responses allowed) & $\mathrm{s}$ & all & $\mathrm{e}, \mathrm{s}$ & $\mathrm{e}, \mathrm{s}$ & $\mathrm{e}, \mathrm{s}$ \\
\hline The following options were known (multiple responses allowed) & $\mathrm{m}, \mathrm{s}$ & all & all & all & $\mathrm{e}, \mathrm{s}$ \\
\hline The following options were experienced (multiple responses allowed) & $\mathrm{s}$ & e & $\mathrm{s}$ & $\mathrm{e}, \mathrm{s}$ & s \\
\hline The following option would be my preference if needed & $\mathrm{e}, \mathrm{s}$ & e & $\mathrm{s}$ & $\mathrm{s}$ & s \\
\hline Time since last EPL (months) & 36 & 7 & 6 & 6 & 18 \\
\hline
\end{tabular}

E: Expectant; M: Medical; S: Surgical; $\mathrm{n}=5$. 
Peters M (2019) Evidence synthesis from a qualitative and a quantitative systematic literature review combined with a focus group interview to identify relevant criteria for decision-making on management options for early pregnancy loss

Table 5. Synthesis of evidence of the qualitative and quantitative studies and the focus group interview.

\begin{tabular}{|c|c|c|}
\hline $\begin{array}{l}\text { Criteria from the literature (qualitative } \\
\text { or quantitative) }\end{array}$ & Quotations from the focus group & $\begin{array}{l}\text { Wording for future } \\
\text { interviews }\end{array}$ \\
\hline $\begin{array}{l}\text { Time spent at the hospital receiving } \\
\text { treatment; Setting of the abort (quant.) }\end{array}$ & $\begin{array}{l}\text { ".. but to know, okay anaesthesia - zag - and then quickly back home " (s) } \\
\text { "No, there is no way that I stay here [in hospital]" (e) } \\
\text { "I was shocked being alone at home" (e) }\end{array}$ & $\begin{array}{l}\text { Avoidance of a treatment in } \\
\text { hospital with anesthesia and } \\
\text { surgery }\end{array}$ \\
\hline $\begin{array}{l}\text { Invasiveness of the method; Chance of } \\
\text { complications requiring more time or } \\
\text { readmission to hospital (quant.) }\end{array}$ & $\begin{array}{l}\text { "It was very important to me, that there was no } \\
\text { injury [of the uterus]" (e) }\end{array}$ & $\begin{array}{l}\text { Avoidance of injuries at } \\
\text { uterus and cervix }\end{array}$ \\
\hline No criteria & No Quotations (see text) & $\begin{array}{l}\text { Avoidance of a blood } \\
\text { transfusion (see text) }\end{array}$ \\
\hline No criteria & No Quotations (see text) & $\begin{array}{l}\text { Avoidance of side effects of } \\
\text { drugs like digestive disorders } \\
\text { (see text) }\end{array}$ \\
\hline $\begin{array}{l}\text { Level of pain experienced; Number of days } \\
\text { of bleeding after treatment (quant.) }\end{array}$ & $\begin{array}{l}\text { "And then it was bearable. So this one event - where I was in strong pain then. It was bearable - definitely. } \\
\text { And I knew where it [the pain] was from - and I was not in fear, that it was unnatural or something" (e) } \\
\text { "But the second time - I was already further [in pregnancy] - I received a suppository to get contractions } \\
\text { - they were intense - I should not have had that (...) and this was agonizing - so a little. You know in this } \\
\text { moment, I know this pain, but from another context - a nice one. (s) } \\
\text { "I thought I am on a horror trip - totally - with all the blood and the pain.." (e) } \\
\text { "First time was easier - than it was gone - there was no blood" (1. s; } 2 \text {. e) } \\
\text { "(...) toilet - just complete- and this mhm - wasn't more than a period bleeding." (e) }\end{array}$ & $\begin{array}{l}\text { Avoidance of burden through } \\
\text { bleeding and pain }\end{array}$ \\
\hline Natural method (quali.) & $\begin{array}{l}\text { "I want to have this naturally - but it was said to me - mhm miscarriages are common and natural and so } \\
\text { I wanted to give my body a chance to handle it one it's own - and to have trust - somehow - despite this } \\
\text { situation. I know - okay - you can have kids - probably and then the body can handle it if is not working." } \\
\text { (e) } \\
\text { "So for me it was actually clear, that I don't want to intervene." (e) }\end{array}$ & $\begin{array}{l}\text { Experience EPL as natural } \\
\text { process/ „let the body handle } \\
\text { it“" }\end{array}$ \\
\hline $\begin{array}{l}\text { Avoiding a procedure that could be } \\
\text { construed as abortion (quali.) }\end{array}$ & “So for me that was no abortion, because I don't have to decide." (s) & Excluded (see text) \\
\hline Fear of seeing the fetus (quali.) & $\begin{array}{l}\text { "I was pregnant with twins. In the end, they lay on my bedsheet. I have seen this - I experienced it traumatic } \\
\text { - really really traumatic - really" (e) } \\
\text { "So I took a picture - indeed“ (e) }\end{array}$ & $\begin{array}{l}\text { Avoidance of seeing the } \\
\text { fetus/ the child }\end{array}$ \\
\hline $\begin{array}{l}\text { Uncertainty when and where the abortion } \\
\text { takes place. (quali.) }\end{array}$ & $\begin{array}{l}\text { „mhm . Clearly, I did not know exactly what to come to me. But I thought, okay - when it becomes to bad, I } \\
\text { will go to the hospital. (e) } \\
\text { "mhm but to have this uncertainty all the time. At this time I had a one and a half-year-old son." (s) }\end{array}$ & $\begin{array}{l}\text { Avoidance of uncertainty } \\
\text { when the abortion takes place }\end{array}$ \\
\hline $\begin{array}{l}\text { Time taken to return to normal activities } \\
\text { after treatment (quant.) }\end{array}$ & $\begin{array}{l}\text { "And I needed this time for me - I needed this time to conclude." (s) } \\
\text { "And the wait - I think - I - somehow I would find that strange" (s) } \\
\text { "(..)in so a hovering state - as if I'm still - somehow the child is still there, but somehow not" (s) } \\
\text { "(...) it was not so close to me because through the surgery it was a completed event." (S) } \\
\text { So I could say, now I go to the hospital, I will have the surgery and when I wake up - then this issue is done. } \\
\text { So personally, this was important for me." (s) }\end{array}$ & $\begin{array}{l}\text { Have a short period of time } \\
\text { until EPL is completed }\end{array}$ \\
\hline
\end{tabular}

S: Surgical, M: Medical, E: Expectant management.

Finally, the focus group sustained partially the results from the literature and showed that the criteria can fit to some extent the German target population. The criterion, the medical procedure is similar to an abortion was excluded as a result of the focus group interview. Regarding potential cultural factors, it is possible that they affect the importance of these criteria and it possibly becomes more important in a society which judges abortion. Also, it seems that the wording/language for the criteria could be improved.

Criteria like recommendations of others or there is too little information about management options were excluded because they do not refer to one of the management options explicitly. It should be mentioned that for example in Germany there is little knowledge about medical and expectant management, so it refers to the management options indirectly.

Some women assessed a criterion as positive while others considered the same as negative; this fits into the review of Wallace et al., which suggests that women have diverse preferences for EPL management [22].

\section{Limitations}

There are some limitations of our study. For example, the small numbers of studies which limit the available evidence. Our search excluded non-English or non-German studies. Although we used established methods for the systematic review of qualitative studies, the analysis techniques to extract data have limitations due to the subjective nature of identifying topics from texts. It is possible that there are more relevant criteria than those we identified. Also, the synthesis from different sources underlies a subjective nature.

We conducted only one focus group with five participants. Hence, the validity of the results is limited.

\section{Conclusion}

Evidence synthesis from qualitative and quantitative literature and a focus group interview could identify relevant criteria for decisionmaking on management options in case of Early Pregnancy Loss. It seems to be important to include the women's perspective into the criteria selection. The identified criteria can be used for further preference elicitation. Also, this study will possibly facilitate plausibility check on the quantitative preference measurement and will help to interpret the quantitative preferences of women.

\section{Acknowledgments}

The authors gratefully acknowledge late S. Droste for conducting the literature search and thank the women who generously participated in our interviews at a stressful time. 
Peters M (2019) Evidence synthesis from a qualitative and a quantitative systematic literature review combined with a focus group interview to identify relevant criteria for decision-making on management options for early pregnancy loss

\section{Ethical standards}

The study was reviewed and approved by the ethics committee of the medical faculty of the Heinrich-Heine University Düsseldorf (approval number: 5398). Informed consent and transparency were considered as main priorities in the study.

\section{References}

1. Vitzthum VJ, Spielvogel H, Thornburg J, West B (2006) A prospective study of early pregnancy loss in humans. Fertil Steril 86: 373-379. [Crossref]

2. Hosang (2013) Abort - course forms. Obstet Gynecol 73: 213-218.

3. ACOG: (The American College of Obstetricians and Gynecologists) (2015) Practice Bulletin No. 150: Early Pregnancy Loss. Obstet Gynecol 125: 1258-1267.

4. Ectopic pregnancy and miscarriage: Evidence Update December 2014.

5. Neilson JP, Gyte GML, Hickey M, Vazquez JC, Dou L (2013) Medical treatments for incomplete miscarriage. Cochrane Database Syst Rev 3: CD007223. [Crossref]

6. Neilson JP, Hickey M, Vazquez JC (2006) Medical treatment for early fetal death (less than 24 weeks). Cochrane Database Syst Rev 19: CD002253. [Crossref]

7. Nanda K, Lopez LM, Grimes DA, Peloggia A, Nanda G (2012) Expectant care versus surgical treatment for miscarriage. Cochrane Database Syst Rev 3: CD003518. [Crossref]

8. Carter D, Misri S, Tomfohr L (2007) Psychologic Aspects of Early Pregnancy Loss. Clin Obstet Gynecol 50: 154-165. [Crossref]

9. Bergner A, Beyer R, Klapp BF, Rauchfuss M (2008) Pregnancy after early pregnancy loss: A prospective study of anxiety, depressive symptomatology and coping. $J$ Psychosom Obstet Gynaecol 29: 105-113. [Crossref]

10. Wallace R, Dehlendorf C, Vittinghoff E, Gold KJ, Dalton VK (2013) Early Pregnancy Failure Management Among Family Physicians. Fam Med 45: 173-179. [Crossref]

11. Muhlbacher AC, Juhnke C (2013) Patient preferences versus physicians' judgement: does it make a difference in healthcare decision making? Appl Health Econ Health Policy 11: 163-180. [Crossref]

12. Harrison M, Milbers K, Hudson M, Bansback N (2017) Do patients and health care providers have discordant preferences about which aspects of treatments matter most? Evidence from a systematic review of discrete choice experiments. BMJ Open 7: e014719. [Crossref]

13. Kittel B, Kaczynski A, Bethge S, Mühlbacher A (2015) What does the new country doctor need?: - An Analytic Hierarchy Process (AHP). Health Econ Quality Manag 21: $137-144$.

14. Elwyn G, Frosch D, Thomson R, Joseph-Williams N, Lloyd A, et al. (2012) Shared decision making: a model for clinical practice. J Gen Intern Med 27: 1361-1367. [Crossref]

15. Danner M, Hummel JM, Volz F, van Manen JG, Wiegard B, et al. (2011) Integrating patients' views into health technology assessment: Analytic hierarchy process (AHP) as a method to elicit patient preferences. Int J Technol Assess Health Care 27: 369-375. [Crossref]

16. Verschoor MAC, Lemmers M, Wekker MZ, Huirne JAF, Goddijn M, et al. (2014) Practice variation in the management of first trimester miscarriage in the Netherlands: a nationwide survey. Obstet Gynecol Int 2014:387860. [Crossref]

17. Herbitter C, Bennett A, Schubert FD, Bennett IM, Gold M (2013) Management of early pregnancy failure and induced abortion by family medicine educators. J Am Board Fam Med 26: 751-758. [Crossref]

18. Bridges JFP, Hauber AB, Marshall D, Lloyd A, Prosser LA, et al. (2011) Conjoint analysis applications in health--a checklist: a report of the ISPOR Good Research Practices for Conjoint Analysis Task Force. Value Health 14: 403-413. [Crossref]

19. http://www.springeropen.com/authors/rats
20. Qualitative Research Checklist: Critical Appraisal Skills Programme. AVlaible from: http://media.wix.com/ugd/dded87_29c5b002d99342f788c6ac670e49f274.pdf

21. Levine K, Cameron ST (2009) Women's preferences for method of abortion and management of miscarriage. J Fam Plann Reprod Health Care 35: 233-235. [Crossref]

22. Wallace RR, Goodman S, Freedman LR, Dalton VK, Harris LH (2010) Counseling women with early pregnancy failure: utilizing evidence, preserving preference. Patient Educ Couns 81: 454-461. [Crossref]

23. Musters AM, Koot YEM, van den Boogaard NM, Kaaijk E, Macklon NS, et al. (2013) Supportive care for women with recurrent miscarriage: a survey to quantify women's preferences. Hum Reprod 28: 398-405. [Crossref]

24. Fleuren M, van der Meulen M, Grol R, Haan Md, Wijkel D (1998) Does the care given by general practitioners and midwives to patients with (imminent) miscarriage meet the wishes and expectations of the patients? Int J Qual Health Care 10: 213-220. [Crossref]

25. Dalton VK, Harris LH, Gold KJ, Kane-Low L, Schulkin J, et al. (2010) Provider knowledge, attitudes, and treatment preferences for early pregnancy failure: $\mathrm{Am} \mathrm{J}$ Obstet Gynecol 202: 531.e531. [Crossref]

26. Bansen SS, Stevens HA (1992) Women's experiences of miscarriage in early pregnancy. J Nurse Midwifery 37: 84-90. [Crossref]

27. Grace S (2014) Author's reply re: The impact of supportive counselling on women's psychological wellbeing after miscarriage - A randomised controlled trial. Int J Obstet Gynecol 122: 595.

28. Moher D, Liberati A, Tetzlaff J, Altman DG (2009) Preferred reporting items for systematic reviews and meta-analyses: the PRISMA statement. PLoS medicine 6: e1000097. [Crossref]

29. Ziegler A, Antes G, König I (2011) Bevorzugte Report Items für systematische Übersichten und Meta-Analysen: Das PRISMA-Statement. $D M W$ 136: e9-e15.

30. Ryan M, Hughes J (1997) Using conjoint analysis to assess women's preferences for miscarriage management. Health Econ 6: 261-273. [Crossref]

31. Petrou S, McIntosh E (2009) Women's preferences for attributes of first-trimester miscarriage management: a stated preference discrete-choice experiment. Value Health 12: 551-559. [Crossref]

32. Graziosi GC, Bruinse HW, Reuwer PJ, Mol BW (2006) Women's preferences for misoprostol in case of early pregnancy failure. Eur J Obstet Gynecol Reprod Biol 124: 184-186. [Crossref]

33. Molnar AM, Oliver LM, Geyman JP (2000) Patient preferences for management of first-trimester incomplete spontaneous abortion. J Am Board Fam Pract 13: 333-337. [Crossref]

34. Wijesinghe PS, Herath RP, Abeysundara ID (2012) A qualitative study on patients' perceptions of expectant management of first trimester incomplete miscarriage. Ceylon Med J 57: 145-149. [Crossref]

35. Limbo R, Glasser JK, Sundaram ME (2014) "Being Sure": women's experience with inevitable miscarriage. Am J Matern Child Nurs 39: 165-174; quiz 175-166. [Crossref]

36. Smith LF, Frost J, Levitas R, Bradley H, Garcia J (2006) Women's experiences of three early miscarriage management options: a qualitative study. Br J Gen Pract 56: 198-205. [Crossref]

37. Olesen, Graungaard AH, Husted GR (2015) Deciding treatment for miscarriage experiences of women and healthcare professionals. Scand J Caring Sci 29: 386-394. [Crossref]

38. Ogden J, Maker C (2004) Expectant or surgical management of miscarriage: a qualitative study. BJOG 111: 463-467. [Crossref]

39. Schreiber CA, Chavez V, Whittaker PG, Ratcliffe SJ, Easley E, et al. (2016) Treatment Decisions at the Time of Miscarriage Diagnosis. Obstet Gynecol 128: 1347-1356. [Crossref]

40. Chavez V, Radcliffe S, Easley E, Barg F, Schreiber CA (2015) Patient-level characteristics and considerations for early pregnancy loss management choice. Contraception 92: 398.

Copyright: (C2019 Peters M. This is an open-access article distributed under the terms of the Creative Commons Attribution License, which permits unrestricted use, distribution, and reproduction in any medium, provided the original author and source are credited. 